\title{
Lo espacial en la poesía de vanguardistas chilenos y en Ecuatorial de Huidobro ${ }^{*}$
}

\author{
The spatial element in Chilean Vanguardia poems \\ and in Ecuatorial by Huidobro
}

Paula Miranda H.

Pontificia Universidad Católica de Chile. Santiago, Chile

pmirandh@uc.cl

\section{RESUMEN}

Basado en el estudio y análisis de un grupo acotado de poemas chilenos vanguardistas y mundonovistas (1920-1930) y de Ecuatorial de Vicente Huidobro (1918), este artículo describe las diversas tematizaciones espaciales, especialmente paisajísticas, correspondientes a sensibilidades artísticas aparentemente divergentes, para demostrar que los poemas, tanto los de avanzada y experimentales como los más residuales, evidencian una sensibilidad moderna muy particular y heterogénea respecto del entorno.

Palabras clave: Vicente Huidobro, vanguardia, poesía chilena, entorno.

\section{ABSTRACT}

Based on the study and analysis of a delimited number of 'vanguardista' and 'mundonovista' Chilean poems (1920-1939) and from Ecuatorial by Vicente Huidobro (1818), this article describes the diverse spatial themes, especially the ones related to landscaping, which correspond with apparently divergent artistic sensibilities, in order to demonstrate that the poems, both the avant-garde or experimental ones and

* Este artículo se realiza en el marco del desarrollo del Proyecto Fondecyt Iniciación $\mathrm{N}^{\circ}$ 11090430, "Identidades territoriales y sujetos en la poesía chilena (1908-1957)", en el que la autora se desempeña como investigadora responsable. 
the more residual ones, evidence a very particular modern sensibility, heterogeneous in the quality of its relation to the environment.

Keywords: Vicente Huidobro, vanguardia, Chilean poetry, environment.

Recibido: 13.07.2011. Aceptado: 13.03.2012

C indaga aquí en los rasgos de distinción que adquirió la poesía de la $\checkmark$ vanguardia chilena, en lo que dice relación con lo espacial en términos temáticos, entre los años 1918 y 1930, especialmente en algunos poemas contenidos en diversas revistas de la época, debido a la gran diversidad de sensibilidades estéticas que ellas registran y por la presencia allí de sistemas artísticos divergentes. Esto a fin de demostrar que en la vanguardia chilena no sólo confluyeron en los primeros años el creacionismo y el surrealismo, sino formas muy heterogéneas de asumir la época renovadora.

Se ha revisado un grupo acotado de poemas pertenecientes a cuatro revistas culturales inscritas en la nueva sensibilidad artística, y se los ha relacionado con uno de los libros vanguardistas más paradigmáticos de la época: Ecuatorial de Vicente Huidobro, publicado en Madrid en 1918. Se estudian en todos ellos las diversas realizaciones espaciales, por ser un tópico común y por concentrarse en este ámbito, de manera sintomática, diversas sensibilidades artísticas, tanto de avanzada y experimentales como más residuales, expresadas en poemas de cuño mundonovista. Entiendo por realización espacial aquella configuración poética referida temáticamente a la dimensión espacial, ya sea de tipo referencial, como es el caso del paisaje (especialmente en lo estético y en el desarrollo de una nueva percepción del entorno) o del territorio (la urbe y lo rural, lo nacional y local, lo cósmico y los espacios interiores), ya sea de tipo no referencial (espacios imaginados, mentales, íntimos o utópicos). Esta configuración se expresa también en el sentido textual, en la lógica del espacialismo, del trabajo con lo gráfico y con lo visual, aspecto este último que no será abordado en el presente estudio.

Los profundos cambios tecnológicos e ideológicos asociados al vanguardismo, como el maquinismo, la modernolatría, el culto a la velocidad, la relativización de lo espacio-temporal, el nuevo subjetivismo, el anarquismo, el materialismo y el nacionalismo, entre otros, se reflejan de manera heterogénea y disímil en estos distintos poemas, no habiendo siempre coincidencia entre su textura y sus contenidos, por lo que se puede asegurar que el vanguardismo poético adquirió diversas fisonomías y realizaciones, más allá de lo que él mismo se propuso como empresa renovadora y de avanzada 
y que fue sin duda el postmodernismo el que permitió, al menos en Chile, el que éste fuera "enraizándose" con fuerza en nuestras latitudes, según lo ha pensado tan lúcidamente Jaime Concha (2008). Gracias principalmente a las aproximaciones de Beigel (2003), Unruh (1994), Bosi (1991), Verani (1990), Schwartz (1983; 1991), Subercaseaux (1999), Osorio (1988), Paz (1985) y Pizarro (1994), hoy es posible asegurar que en las expresiones artísticas y culturales más relevantes de las vanguardias latinoamericanas (y también en cierto mundonovismo) hubo diálogo de lo propio y lo ajeno; se miró a Europa, pero también a nuestro continente, importó registrar la experiencia nueva de los acelerados cambios tecnológicos, pero también se dio cuenta de una nueva subjetividad frente a esos cambios. Si bien estos y otros estudiosos han puesto mayor atención en la revisión de revistas y grupos, lo que ha dado paso a la compilación de numerosos epistolarios y manifiestos, se ha seguido privilegiando la caracterización de las figuras más emblemáticas de la época, como Neruda o Huidobro, descuidando la necesaria atención que debe darse al trabajo de numerosos poetas e intelectuales de la época, impactados todos ellos en diversos grados por el movimiento renovador y quienes mantuvieron diversas redes de colaboración y de difusión, sobre todo de divulgación de poetas y ensayistas de avanzada, especialmente a través de la publicación de numerosas y variadas revistas, las que en el caso chileno han sido ampliamente estudiadas por investigadores destacados como Patricio Lizama (2008), Dieter Oelker (1987) y Klaus Müller-Bergh (1998), investigador este último que se ha acercado a las revistas Claridad, Elipse, Nguillatun, Dínamo y Caballo Verde para la poesía.

Hay que destacar que en general las aproximaciones existentes no siempre precisan la especificidad de la poesía en el sentido de su condición de género no mimético desde mucho antes de la vigencia de las vanguardias. Generalmente se asimila la estética vanguardista a la modernolatría y a la nueva concepción de tiempo y del espacio, propias de los cambios en lo material y en lo social, pero se descuida la profunda transformación que estaba ocurriendo en la concepción que se tenía de la poesía y en las nuevas formas que ella adquiriría. Nos alejamos por tanto aquí de las aproximaciones que asimilan mecánicamente cambio social y cambio estético, como si lo ocurrido en lo real en esos años de radicales cambios, siempre y necesariamente se expresase en lo artístico en el mismo sentido. Creemos que el discurso poético desea no sólo comunicar los nuevos temas de la modernidad, sino recrear la vivencia sensorial y perceptiva de esa experiencia, la que a veces excede sus vínculos con lo real e imagina nuevas posibilidades sensoriales: De Rokha es considerado por Joaquín Edwards Bello como un "hipereste- 
siado de la sensibilidad" y en el poema "La gran Rueda" de Neftalí Agrella los "solteros" consumen "pastillas de sensaciones". Hay que considerar aquí que no sólo estaba cambiando la realidad, sino también las formas de representar o relacionarse con esa realidad desde el arte. Si nos detenemos en las búsquedas de este nuevo arte, el que se había propuesto dar fin a la mímesis (Huidobro, desde 1914), independizarse para siempre de la música, renunciar a la belleza y a la referencialidad (Fernández Moreno, 1962), habría que sostener entonces que lo más importante de este arte nuevo es no sólo dar cuenta de una nueva vida material (cuerpo, máquina, relativización del tiempo-espacio en la ciudad e impacto de las nuevas tecnologías), sino ser expresión de una nueva vida espiritual y artística, como tan bien lo pensó Yurkievich, marcada por la inteligencia, la creación y la imaginación. Sobre ese mundo obviamente en transformación, pero en "lenta" transformación, sobre esas realidades vistas de otra manera por la ciencia y el progreso, sobre la velocidad y el movimiento impuestos por el automóvil y el tren, se ejerció una mediación poética, sobre todo en un momento en que ya lo real no le serviría de modelo al arte, sino que éste crearía o bien sus propios modelos o bien sus propias interpretaciones de esos modelos.

El análisis que aquí realizo ha tenido como objetivo diferenciar lo esencial de estos poemas respecto de otros registros que también hallamos en las revistas que nombraremos más adelante (mundonovistas, modernistas, románticos, etc.) y también distinguir diversas tendencias históricas del vanguardismo en cada uno de ellos (creacionismo, surrealismo, tremendismo, futurismo, cubismo, etc.). El corpus escogido ha sido seleccionado de poemas presentes en las revistas Andamios (Asociación General de Profesores de Chile) y Andarivel, ambas publicadas en Santiago entre 1925 y 1927; y Litoral (1927-1928) y Nguillatun (1924), ambas de Valparaíso, además del largo poema Ecuatorial de Vicente Huidobro, publicado en 1918. Hay que señalar que muchos de los poetas que publicaron en estas revistas fueron consignados en la más importante antología vanguardista de la época, el Índice de la nueva poesía americana (Buenos Aires, 1926), editada por Vicente Huidobro, Alberto Hidalgo y Jorge Luis Borges. En esta antología efectivamente se consignaron muchos de los nombres de poetas que o bien alentaron el arte nuevo o bien publicaron en este rico periodo de producción posmodernista y vanguardista, destacándose entre ellos Fenelón Arce, Rubén Azócar, Ángel Cruchaga Santa María, Rosamel del Valle, Pablo De Rokha, Juan Florit, Juan Marín, Pablo Neruda, Salvador Reyes y Alberto Rojas Jiménez. No aparecen en esta importante publicación, sin embargo, poetas que publicaron o dirigieron revistas fundamentales, como Neftalí 
Agrella, Pedro Plonka, Winett De Rokha o Juan Moraga, entre muchos otros. Por su parte, Huidobro, ya había producido lo más importante de su poesía creacionista-cubista, sobre todo en Europa, y había alentado y propiciado entre los poetas de las nuevas generaciones la necesidad del arte nuevo, habiendo publicado para esos años junto a otros la revista $A z u l$, Musa Joven, Nord-Sud y Creation, estas dos últimas en París. De entre la producción huidobriana de la época plenamente creacionista, aquella que va desde 1916 a 1925 (o desde 1918 a 1925, según René de Costa), he destacado el importante poema largo Ecuatorial, publicado en Madrid en 1918 y en el que la poesía de Huidobro recurre sistemáticamente al espacialismo para, además, tematizar esencialmente un espacio europeo y latinoamericano fracturado por la guerra, a través de la poetización de un estar fuera del tiempo y del espacio, sensación provocada en Huidobro por la traumática experiencia de la guerra y de sus signos escatológicos, bajo el temple del testimonio y la estupefacción: "QUÉ DE COSAS HE VISTO".

Como hipótesis preliminar podemos plantear que si hay algo que cambió radicalmente en el arte nuevo expresado en la poesía chilena, esto fue la configuración de nuevos y variados espacios, recorridos o creados bajo una nueva sensibilidad, intelectual e imaginativa, en algunos casos con fuertes rastros de estéticas anteriores, especialmente mundonovistas, en lo que ellas tienen de indagación en espacios intermedios, interiores e íntimos. En este sentido, afirmo que fueron los poetas mundonovistas los que primero recorrieron el territorio afectado parcialmente por la incipiente modernización, fueron ellos los que a través de la "exteriorización de sensaciones" (Pedro Prado) o bien de la mirada sobre lo exterior (Pezoa Véliz), registraron en Chile por primera vez la "intimidad conflictiva" de la nueva vida en las ciudades. Es por esto que en el caso de Huidobro esa estética postmodernista hace parte central de toda su obra entre 1911 y 1914 . En el caso de los poetas de las revistas vanguardistas estudiadas, hay una mezcla de espacialidades mundonovistas y vanguardistas, aunque cada poeta se defina por una u otra. Además, parecería no existir en estas nuevas estéticas la despersonalización tan destacada como rasgo moderno europeo (Friedrich) ${ }^{1}$; muy por el con-

${ }^{1}$ Dentro de la negatividad como rasgo distintivo de la "lírica moderna", Friedrich plantea que el poema trata de evitar la familiaridad comunicativa, no expresando ya los sentimientos del yo personal del poeta. En este sentido se despersonaliza el sujeto poético y por ello es un arte más bien "deshumanizado". Cita para fundamentar su aseveración la tan conocida frase del Marinetti del Manifiesto Futurista de 1909: "El sufrimiento de un ser humano no nos resulta más interesante que el sufrimiento de una lámpara en un cortocircuito". (El hombre en esta poesía sigue estando presente, pero ahora en la forma de mero soporte del lenguaje y como fantasía creadora). En Friedrich, Hugo (1959). Hoy podemos discutir y complejizar más aún este concepto, considerando 
trario, aquí los espacios provocan en quien habla distintos grados de subjetividad, siguiendo en algunos casos el dictamen romántico del poeta profeta, y en otros, asimilándose esa voz a la materialidad del espacio representado, como en "Paisaje" de Vicente Huidobro, en donde el hablante es reemplazado por una suerte de soporte de un paisaje analizado y organizado a través del ejercicio de la memoria y del deseo. La dimensión material del paisaje alcanza el lugar de la enunciación, espacializándolo y difuminándolo: "Al atardecer nos pasearemos por rutas paralelas", dice el verso final del poema "Paisaje" del Huidobro de Horizon Carré; y a medida que se expresa el deseo a nivel del enunciado, se dibuja un nuevo camino en la enunciación (la línea que cierra el cuadro). En este sentido, la despersonalización será articulada en nuestro continente como un juego de máscaras para la enunciación, y no como la ausencia de subjetividad o emotividad, como lo plantearon los futuristas ${ }^{2}$. Un ejemplo interesante es la creación del personaje Altazor, con voz propia en gran parte de los siete cantos de Altazor o el Viaje en paracaídas de 1931. Allí, el propio Altazor se multiplica en muchos posibles e interpela a su autor real, haciendo comparecer a éste en un juego heteronómico muy singular:

Yo tú él nosotros vosotros ellos

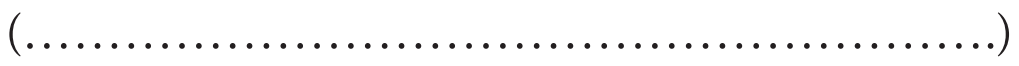

Justicia ¿qué has hecho de mí Vicente Huidobro?

(Huidobro, 2003: 743).

\section{APROXIMACIONES AL VANGUARDISMO}

En una de las hojas de Nguillatun, revista publicada en Valparaíso bajo la impronta vanguardista, se consigna un cartel que reza: "Se aceptan colaboraciones sólo de carácter moderno”. Pero ¿qué es lo moderno para estos poetas o qué implicó la modernidad para la poesía chilena? ¿O fue vanguardista todo lo moderno? O ¿quién y desde dónde se definía lo moderno?

que las formas que adquiere la despersonalización no se refieren únicamente a la "ausencia" de sentimentalismo, sino que incluyen estrategias de enmascaramiento y desdoblamiento, propios del drama.

${ }^{2}$ Habría que agregar además que fue el mundonovismo quien profundizó la diferenciación entre el yo fenoménico y el yo textual, rasgo que ya había anunciado el propio Darío (Cf. Le Corre, 2001.) 
$\mathrm{O}$ ¿era lo mismo ser moderno en poesía que en otras artes o disciplinas? El género lírico ya había sufrido una total mutación durante los primeros momentos de la modernidad. De ahí que Pasquier en el siglo XVI ya destacase la avant-garde de la poesía, en contraposición a los poetas antiguos y ya definitivamente en la lógica del progreso (Calinescu, 1991). Esta condición moderna había provocado que la poesía abandonase su interdependencia de lo moral y lo religioso y que deslindara además su lugar respecto de la prosa, específicamente de la novela, autoerigiéndose ella misma como aquel discurso desterrado del mundo burgués (Paz, 1985). Esta modernidad también implicaba abandonar definitivamente el vínculo antes indisoluble entre la música y la poesía. Sabemos hoy que fue el modernismo en América Latina, la formación que por primera vez enfrentó como amenazas para el arte la secularización y la mercantilización (fines del siglo XIX). De ahí la queja de Darío en Prosas profanas y otros poemas (1896): "yo detesto la vida y el tiempo en que me tocó nacer". Herederos del espíritu romántico europeo (según Paz y Gutiérrez Girardot), los modernistas de América Latina privilegiaron por ello la inquietud metafísica, la aspiración analógica, el sustrato mítico y ritual, la recuperación de la musicalidad y la aspiración sagrada en clave blasfema.

Las vanguardias, por su parte, radicalizaron su oposición a la tradición y su relación crítica con la modernidad y desde 1914 mantuvieron en varios momentos algunos de los rasgos modernistas, pero se abrieron hacia otras dimensiones de lo moderno. En muchos sentidos los poetas experimentaron la modernización como una oportunidad: como posibilidad de experimentación y gran libertad, como fomento de la individualidad y de profundización en nuevos niveles de lo real, como diálogo productivo con las culturas "primitivas", como percepción de la nueva cronotopía y materialidad del mundo y como experiencia subjetiva y a veces crítica de la ciudad, como nuevas posibilidades de despersonalización. En esta etapa vanguardista, la poesía se enfrentó a lo moderno bajo el signo de la creatividad, la ensoñación, la imaginación y el espíritu productivo del destierro (enajenación de la conciencia).

En general, los movimientos de vanguardia se caracterizaron por incorporar las nuevas percepciones de los individuos, como la fragmentación y el desarraigo; las expresiones del mundo moderno representadas por la ciudad y la tecnología; la exploración de territorios desconocidos como el inconsciente; y la unión del arte a la vida, todo lo cual implicó un radical rechazo a la tradición y al poder establecidos. En el editorial de la revista porteña Nguillatun se consigna qué es lo que se le está exigiendo a este arte de avan- 
zada: "el mismo anhelo de vitalidad literaria, el mismo ensueño que agita, en el escenario de sus ciudades humosas y puertos bruñidos, a los poetas, músicos, estetas y teorizantes libres de este siglo" (Nguillatun, editores, 1). Además, Federico Schopf ha señalado que el vanguardismo asumió que "las relaciones de tiempo y espacio pierden su homogeneidad" y que "se relativizan como puntos de apoyo para ordenar la realidad y la experiencia" (Schopf, 1986).

De esta manera, el discurso poético deseaba no sólo comunicar los nuevos "temas" de la modernidad, sino que hizo como que recreaba la vivencia sensorial de esa experiencia (tecnologización, viaje, mutación del sensorium), hiperbolizando en muchos casos esos cambios e independizándose del referente y del emocionalismo. Una poesía que en América Latina radicalizaba su intención de cambio y de ruptura y que a la vez revitalizaba su afán identitario (Rama), ya sea en su tendencia más cosmopolita (Schwartz), ya sea en la más transculturada (Rama), ya sea en aquellos poetas más exterioristas o bien en los retrotraídos hacia la vida interior (Nómez).

Como aparentemente se ha superado la función social de la poesía y también la función subjetiva o de expresión de la interioridad, tan propias de la tradición romántica, esta poesía vanguardista crea sujetos de la enunciación tensionados por máscaras textuales que se mueven entre la total despersonalización (futurismo) y la profunda inquietud metafísica (Neruda o el Huidobro de Altazor), entre la aspiración profética y lo inefable, entre el automatismo o las fuerzas del subconsciente (surrealismo) y la racionalidad sugerente y creadora (creacionismo). Sin embargo, hay que afirmar que la total despersonalización, tan propia de mucha poesía moderna, según Friedrich, opera en estos poemas de manera muy relativizada y circunscrita, como ya hemos venido insistiendo.

\section{ECUATORIAL Y LOS NUEVOS SIGNOS}

En la etapa plenamente creacionista-cubista (1918-1925) y bajo una conciencia trascendentalista, Huidobro configura una cosmología estética a plenitud, que abandona cualquier marca local específica y apuesta por los territorios mentales, personales y espirituales del hombre, sin nunca abandonar el fundamento cosmológico: "Yo me alejé / pero llevo en la mano/ Aquel cielo nativo", dice en Poemas Árticos (2003).

Recuérdese que el primer Huidobro, el que va de Ecos del alma (1912) a Las pagodas ocultas (1914), está todavía bajo la estética modernista y a veces 
utiliza recursos románticos, aunque muy pronto pasa a una preocupación por los espacios interiores de la nación, ahistóricos y que portan de todas maneras un deseo de arraigo, muy en la lógica del mundonovismo epocal y de la poesía de los suburbios. En esa poesía temprana Huidobro tematizó no sólo aldeas o rincones de los arrabales, sino también personajes y leyendas populares chilenas, bajo claros signos de una nueva sensibilidad y mirada.

Lo que habrá luego en Ecuatorial $(1918)^{3}$ es la obsesiva preocupación por "los puntos cardinales" y temporales que circundan al hombre, en un momento en que la guerra y la destrucción amenazan la fijeza y estabilidad de estos referentes y clausuran para siempre la posibilidad de percibir lo real de la misma manera que antes: "las ciudades de Europa/ se apagan una a una" (2003: 491):

Era el tiempo en que se abrieron mis párpados sin alas

Y empecé a cantar sobre las lejanías desatadas

Saliendo de sus nidos

Atruenan el aire las banderas

\section{LOS HOMBRES}

\section{ENTRE LA YERBA \\ BUSCABAN LAS FRONTERAS (2003: 491).}

Un sujeto ilimitado en su comprensión abarcadora del mundo se enfrenta contradictoriamente a un mundo que inventa límites ahí donde naturalmente no los hay y cuyo efecto más devastador será la guerra. La "nueva" realidad en este Huidobro, no es una creada por la fuerza mental, sino una más miserable, la de la guerra real. Las "banderas" (símbolo de la nación) son una realidad reciente (saliendo de sus nidos) y de ahí la imagen de hombres buscando con dificultad las demarcaciones de sus fronteras, pues éstas no existen más allá de la mera realidad jurídica. El hablante desdibuja los límites nacionales (y de la página) para observar el entorno, pero desde una mirada que no es capaz ya de volar ni de circundar el mundo, pues lo único que se evidencia es la realidad de la guerra:

\footnotetext{
${ }^{3}$ Según Cedomil Goic el libro fue escrito en París en marzo y abril de 1918 y se publicó en agosto en Madrid, la edición tuvo un tiraje muy limitado. En las obras completas compiladas por Braulio Arenas (1964) y Hugo Montes (1976) se han alterado bastante los textos originales, sobre todo en sus aspectos espaciales y gráficos.
} 
Sentados sobre el paralelo

Miremos nuestro tiempo

SIGLO ENCADENADO EN UN ANGULO DEL MUNDO

(2003: 492).

Tiempo atrapado y entrampado en el espacio. Ese espacio es urbano, el que está signado también en algunos casos por su contraposición con los espacios naturales (cielo, mar, montañas) y por la mirada distinta que sobre la ciudad imprime el nuevo sensorium humano. Los únicos que pueden reestablecer el vínculo universal (mundano claro está) son las nuevas máquinas de las comunicaciones: el teléfono y el telégrafo, pero sobre todo el ferrocarril, presente en Ecuatorial bajo la imagen vivificante de la locomotora. Tiene conciencia Huidobro de que este ente "viviente" que es el tren transforma la percepción de los seres humanos y la realidad que los circunda. Por ello la "locomotora" vence el tiempo, ella "en celo" es "el Diógenes con la pipa encendida/ Buscando entre los meses y los días". Se establece una relación analógica entre el hablante y ella: "Mi alma hermana de los trenes" y la representación descoloca la imagen del objeto en movimiento para privilegiar la percepción humana subjetiva y desde su interior: "Un tren puede rezarse como un rosario", "El tren es un trozo de la ciudad que se aleja". Incluso más, es posible que la propia naturaleza adquiera las características de esta máquina a vapor:

La cordillera andina

Veloz como un convoy
Atraviesa la América Latina (2003: 502).

En Ecuatorial no sólo se deroga el entorno espacial, sino también el tiempo pierde corporalidad, marcando un antes y un después en la historia: "Mi reloj pierde todas sus horas/ Yo te recorro lentamente/ Siglo cortado en dos" (2003b: 501). Se clausuraba así con la guerra cualquier intento analógico, cosmológico e incluso creacionista; en su lugar la ciudad se presentaba en proceso de desmaterialización, a través de imágenes que personificaban objetos bajo una pulsión violenta y destructiva: "silba la locomotora en celo", "Cada estrella/ es un obús que estalla", "Los ocasos heridos se desangran". Incluso los "puntos cardinales" han sido reducidos a botín de guerra, junto a "raros animales / Y árboles exóticos", indicando que no son sólo las materialidades de los territorios lo que aquí está en disputa, sino la supervivencia total del espacio que circunda al hombre. Sin embargo y pese a todo, este hablante 
exclama "QUÉ DE COSAS HE VISTO” y sostiene una enorme preocupación social que hacia el final trasmuta la escatología en cierta esperanza:

Llegamos al fin de la refriega

Mi reloj perdió todas sus horas

Yo te recorro lentamente

Siglo cortado en dos (2003: 501).

Podemos pensar entonces que las vanguardias, además de complejizar la mirada y la percepción de nuestros poetas, les permitió pensar y poetizar lo propio bajo diversos ángulos, en un ejercicio que en lo estético podría ser considerado cubista, pero que en lo ético dio paso a cierto clima de escepticismo y desesperanza, más propio del Huidobro de El ciudadano del olvido que del plenamente vanguardista.

\section{ESPACIOS Y POETAS INTERMEDIOS}

Los poetas aquí estudiados publicaron sus textos en dos revistas de grupos de intelectuales del puerto de Valparaíso: Nguillatun. Periódico de Literatura y Arte Moderno, de la cual se publicó el primer número consistente en cinco páginas y una declaración programática de defensa de lo indígena y lo nacional y Litoral. Órgano de estética, arte moderno y ciencia, publicada por "el grupo" entre 1927 y 1928 y que dio vida a tres copiosos números. Los restantes poemas se encuentran en dos revistas publicadas en Santiago y que reúnen a importantes intelectuales de la época: Andamios (1925) pertenece a la Asociación de Profesores y tiene gran influjo de Pablo Neruda; y Andarivel. Revista bimestral de arte y crítica, la que publicó su único número en el año 1927. En todos los casos, los editores declaran su abierta adscripción al arte nuevo, lo que se refleja en sus editoriales, manifiestos, carteles y traducciones, pero sobre todo en el carácter de sus poemas. En ellos claramente conviven un fuerte sustrato mundonovista, a veces más temático, otras veces más textual, con evidentes signos vanguardistas, existiendo, en algunos casos, poemas definitivamente vanguardistas, aunque de diversos registros: unos más futuristas en clave modernólatra o de nueva sensibilidad, otros más centrados en la nueva percepción espacial (velocidad, viaje, desgarro en la ciudad); unos construidos de manera más lineal, otros preocupados por la yuxtaposición y la experimentación formal. En cualquier caso, no es 
aquí la experiencia de la guerra la que impacta el poema (como ocurría en Ecuatorial), sino la experiencia interior de los cambios modernizadores desarrollados de manera gradual y tenue todavía para la época. Es una estética que constata la condición de territorios en proceso de transformación: del campo a la ciudad, de la aldea al suburbio, de la estabilidad a la errancia. Por ello se mezclan aquí imágenes del paisaje natural, intervenidas por la máquina y su dimensión material; de ahí que haya en estos poemas cierta tensión o contradicción. Una estética en la que está influyendo lo nuevo como búsqueda, pero enfrentada a una realidad todavía semindustrial y semiurbana. Cuando Mistral reflexiona sobre esto hacia 1928, parece acertar con su descripción: "Sensibilidad nueva significa mirada inédita, pero que cae sobre las cosas con que nos codeamos, sea huerto o majada. Me hacen sonreír algunos libros que llegan de rincones ruralísimos de América: están atravesados, están veteados de fabrilismo, de maquinismo, de Torre Eiffel, de Picassos y de Paul Morands, y han sido pensados mientras se oía la rumia búdica de las vacas o el cordón lacio del agua de riego" (Mistral, 1978). La andanada contra el "fabrilismo" y el "maquinismo" no tiene en ella nada de insólito, evidentemente Mistral no podía menos que ver en la fetichización de la técnica una adicción perturbadora y aun peligrosa. El propio Huidobro, en su artículo "Futurismo y maquinismo", años más tarde, advertirá también el riesgo del maquinismo sin fundamento: "Creo que ciertos poetas actuales están creando una mitología, la mitología de la máquina [...] Estoy seguro de que los poetas del porvenir tendrán horror de los poemas con muchas locomotoras y submarinos" (Huidobro, 2003).

Los poetas de estas revistas no alcanzan a convertirse en esos modernólatras criticados por Huidobro o parodiados por Mistral, porque aunque atisban y se impactan con las nuevas tecnologías, el acento está puesto en las nuevas sensaciones y experiencias respecto de ellas. En estas revistas se encuentran poemas en que convive la transmisión de sensaciones del mundonovismo con la creación de percepciones del vanguardismo. Los rasgos posmodernistas se registran ya sea en poemas específicos de manera exclusiva o bien comparten estas características con rasgos marcadamente vanguardistas en un mismo poema, superponiendo una mirada de nueva sensibilidad a un paisaje relativamente estático y ligado todavía miméticamente a la naturaleza. En este último caso hay percepción de nuevos espacios (lo fabril irrumpe en medio de imágenes oceánicas en poemas sobre puertos, por ejemplo), o nueva percepción.

El espacio en los poemas más vanguardistas no es la urbe definitiva, sino que es lo rural en transformación y lo urbano semindustrial, son espacios 
imaginados o ensoñados, como es el caso del poema sutil "Boudoir" de Pedro Plonka (Litoral No 2, 1927). Aquí, casi en un acto de conjuro y maravilla, se realiza la transfiguración de un pequeño cuarto de vestir a partir del deseo erótico. Lo espacial se construye en varios sentidos: el yo-tú amoroso entrelaza su pulsión en medio de un espacio tipográfica y temáticamente yuxtapuesto. Imágenes de inmensidad y pequeñez, de protección y ensoñación transfiguran el cuarto de vestir, saturado de recuerdos y artículos culturales, los que vuelven a la vida gracias a la fuerza del eros y de los sonidos musicales modernos del "jazz band".

Si tuviésemos que establecer las principales preocupaciones vanguardistas de los poemas contenidos en estas revistas, en el ámbito de lo espacial, podríamos señalar las siguientes: los paisajes están en construcción, por lo que son lugares intermedios, en un sentido diverso al planteado por el mundonovismo; acusan, además, cierta subjetividad que ha superado el emocionalismo anterior y que recurre a formas muy heterogéneas de despersonalización, según lo hemos venido señalando; y, por último, los poemas configuran en algunos casos un "espacio intertextual", en que se dialoga con formatos o temas de otras tradiciones, iniciando con esto un rasgos fuertemente presente a partir de los años 50 en Chile: el arte de doble codificación y el diálogo con discursos de la cultura del espectáculo. Importante aquí son los poemas de Juan Florit, Neftalí Agrella y Julio Walton.

Respecto del primer rasgo, esta vanguardia de lugares locales intermedios, registra la experiencia urbana muy débilmente, se centran más bien y sobre todo en lugares o espacios asociados a los procesos de modernización en puertos, en pueblos y en pequeños ciudades, en las primeras impresiones del automóvil, de los parques de diversión y del espacio aéreo. En muchos casos los poemas dialogan o representan el puerto como un lugar interdicto entre la fuerza de la naturaleza y la fuerza de la máquina productiva. Es el caso del poema "Tipperary" de Pedro Plonka, en el que la maquinaria del puerto parece dinamizar aún más la fuerza del océano: "LAS GRÚAS LLAMAN A PUERTO A LOS NAVÍOS/EL MAR ABRE SU COLOSAL ABANICO DE PUERTOS”; o bien, las imágenes para describir el movimiento incesante del puerto están tomadas del imaginario rural, afectado en parte además por el "ojo fílmico": "FILM DE MARINERÍAS VENDIMIANDO EN LAS RADAS/ EN DONDE LAS CHIMENEAS ARAN EL CAMPO AZUL".

Frente a estas temáticas algunos hablantes toman distancia crítica y experimentan con formas impersonales (verbo en infinitivo del futurismo) o bien incorporan la dinámica de la velocidad a la mirada ("Cocktail", "Poema de 
las Catástrofes", "Tipperary”, “Torbellino”, "Ciudad Despanzurrada”). En otros, con mayor presencia del subjetivismo, los poemas son críticos de la máquina, la velocidad y la urbe (casi ninguno es modernólatra). Muy importante en este sentido es el tránsito registrado entre la experiencia urbana y la rural, habiendo en muchos casos poemas que mezclan imágenes de la ciudad con imágenes naturales o de la vida en el campo, como por ejemplo lo ocurrido con el poema "Pueblo" de Alejandro Gutiérrez o la nostalgia por el pasado que se está clausurando en "Canto de las voces silvestres" de Zoilo Escobar.

En el poema "Auto", Salvador Reyes (1928), publicado en la Revista Litoral, en diálogo aparente con los puntos 4 y 5 del "Primer Manifiesto Futurista" de Marinetti (1978 [1909]), mezcla hiperkinéticas imágenes de velocidad exterior y corporal con paisajes naturales, que persisten en su quietud y parsimonia:

Nuestra piel es la pista de las velocidades

Flecos de viento flamean en torno a nuestro cuerpo

Un ritmo preciso acompaña el vértigo de las cosas.

Los árboles, las casas, arrancadas de raíz

Se precipitan sobre nosotros.

El camino no alcanza a desenrollarse

Con la velocidad que se le impone

Mientras el cielo gira pausadamente sus aspas

Como un ventilador descompuesto.

Esa velocidad estrepitosa, imaginada claro está, se contradice no sólo con el dato real de que para 1905 la ordenanza municipal permitía a los automóviles transitar a no más de $15 \mathrm{~km} / \mathrm{h}$ en América Latina, sino también, con la segunda parte del poema, en la que el cuerpo se analoga con la velocidad para, en un gesto rokhiano por lo dionisíaco y cosmológico, convertirse en un sujeto omnipotente y utópico en un mundo que recién comienza. Y aquí entonces es donde la mirada vanguardista espacial se impone, porque pese a pasearse en automóvil por los caminos, la percepción poética sigue siendo cosmológica, analógica y mental.

El segundo rasgo aquí destacado, el de una vanguardia retrotraída hacia la vida interior (hipervital, según Fernández Moreno), está marcado por rasgos del surrealismo, del tremendismo (Pablo De Rokha), de lo dionisíaco y del intimismo (poema "Boudoir"). A esta preocupación por la subjetividad se agrega también el registro de la nueva experiencia sensorial: la convivencia heterogénea con las máquinas ("La Gran Rueda" de Agrella y "La Rueda" 
de Winett De Rokha); la experiencia de la velocidad ("Auto", “Torbellino"); la cultura del espectáculo ("La Gran Rueda", "Marítima”, "Buenos Aires"); el tema amoroso en nuevos registros perceptivos ("Boudoir", "Poema", "La amada austral”); y la experiencia cosmopolita y del viaje (Agrella, Florit).

En general entonces, y como hipótesis tentativa, podemos argumentar que tanto la vanguardia huidobriana como la que registran algunas revistas vanguardistas de la década del 20 en Chile, si bien dialogaron y desearon instalar el arte nuevo en nuestro país, no lo hicieron imitando las formas europeas únicamente, sino que se apropiaron de algunos de sus recursos temáticos o formales, o bien propusieron los propios, y agregaron a la nueva sensibilidad una manera específica de enfrentar los drásticos cambios que empezaban a operarse en la experiencia poética y en el registro vital de la época. En todos los casos se mezclaron miradas residuales con las emergentes y, lo más importante, dialogaron fuertemente con sus respectivas épocas sin renunciar a la capacidad del poema de crear espacios alternativos o de interpretar lo paisajístico bajo nuevas miradas, percepciones y ensoñaciones. La subjetividad vanguardista se hizo sentir de una manera en que se matizaron la despersonalización, cierta inquietud metafísica (Huidobro) y la nueva experiencia sensorial de la modernidad.

\section{REFERENCIAS}

Agrella, Neftalí y Pablo Garrido. s/datos. "Nuestro Programa”, en Nguillatun. Periódico de Literatura y Arte Moderno 1, pp. 1.

Beigel, Fernanda. 2003. El itinerario y la brújula. El vanguardismo estéticopolítico de José Carlos Mariátegui. Buenos Aires: Biblos.

Bosi, Alfredo. 1991. "La parábola de las vanguardias latinoamericanas". En Jorge Schwartz (Ed). Las vanguardias latinoamericanas. Textos programáticos y críticos. Madrid: Cátedra, pp. 13-24.

Calinescu, Matei. 1991. Cinco caras de la modernidad. Modernismo, vanguardia, decadencia, kitsch, posmodernismo. Madrid: Tecnos.

Concha, Jaime. 1998. "Función histórica de la Vanguardia: El caso chileno", en Revista De Crítica Literaria Latinoamericana 48, pp. 11-23.

Fernández Moreno, César. 1962. Introducción a la poesía, México: Fondo de Cultura Económica.

Friedrich, Hugo. 1959. Estructura de la lírica moderna. Barcelona: Seix Barral. Huidobro, Vicente. 2003. Huidobro, Vicente, Obra Poética. Edición crítica de Cedomil Goic. Madrid, España: Allca XX. Colección Archivos. 
Le Corre, Hervé. 2001. Poesía hispanoamericana posmodernista. Historia, teoría, prácticas. Madrid: Editorial Gredos.

Lizama, Patricio. 2001. "Emar y la vanguardia artística chilena en La Nación (1923-1927)”, en Anales de Literatura Chilena 2, pp. 191-207. . 2008. "La revista Ariel: manifiestos y voces de la vanguardia". Revista Chilena de Literatura 72, pp. 235-254.

Marinetti, Fillippo Tommasso. 1978 [1909]. "Primer Manifiesto Futurista”, en Manifiestos y textos futuristas. Barcelona: Ediciones del Cotal, pp. 129132.

Mistral, Gabriela. 1978. "Página para Pedro Salinas". En Gabriela piensa en... Roque Esteban Scarpa (Ed). Santiago de Chile: Andrés Bello, pp. 254-257.

Müller-Bergh, Klauss. 1998. "De Agú y anarquía a la Mandrágora: notas para la génesis, la evolución y el apogeo de la vanguardia en Chile", en Revista Chilena de Literatura 31, pp. 39-46.

Oelker, Dieter. 1987. "La revista Letras a través de su índice", en Acta Literaria 12 , pp. 83-122.

Osorio, Nelson. 1988. Manifiestos, proclamas y polémicas de la vanguardia literaria hispanoamericana. Caracas: Biblioteca Ayacucho.

Paz, Octavio. 1985. "Rupturas y restauraciones". El Paseante 23-25, pp. $17-$ 23.

Pizarro, Ana. 1994. Sobre Huidobro y las vanguardias. Santiago de Chile: Usach.

Reyes, Salvador. 1928. "Auto", en Revista Litoral 3, marzo, pp. 5.

Schopf, Federico. 1986. Del Vanguardismo a la Antipoesía. Roma: Bulzoni editore.

Schwartz, Jorge. 1991. Las vanguardias latinoamericanas. Textos programáticos y críticos. Madrid: Cátedra.

. 1993. Vanguardia y Cosmopolitismo en la década del veinte: Oliverio Girando y Oswald de Andrade. Buenos Aires: Beatriz Viterbo Editora.

Subercaseaux, 1999. Bernardo. Genealogía de la Vanguardia en Chile. Santiago: Ed. Universidad de Chile.

Unruh, Vicky. 1994. Latin American Vanguards. The art of contentious encounters. California: University of California.

Verani, Hugo. 1990. Las vanguardias literarias en Hispanoamérica. Manifiestos, proclamas y otros escritos. México: FCE.

. 1995. "Estrategias de la vanguardia", en América Latina. Palabra, Literatura y Cultura. Vol 3. Vanguardia y modernidad. Sao Paulo: Unicamp, pp. 77-87. 